\title{
Lecturas ácratas en torno a la Revolución cubana
}

\author{
Daniel R. Trejo \\ Programa de Posgrado en Estudios Latinoamericanos - Universidad Nacional Autónoma de México \\ rotesdaniel@gmail.com \\ ORCID: 0000-0001-8540-8280
}

Title: Anarchist Readings about the Cuban Revolution

Resumen: A 60 años de haber triunfado, la Revolución cubana sigue suscitando apasionados debates sobre su significación y realidades, pues despertó la esperanza de un cambio profundo en los sinos de los pueblos americanos. Sin embargo, una familia de izquierda la cuestionó en sus orígenes mismos, advirtiendo muy temprano el peligroso giro dado hacia el socialismo de estilo soviético. En esa tesitura este artículo examina cómo reaccionaron y qué lecturas elaboraron los anarquistas ante ese proceso. El análisis se realizó a partir de diferentes publicaciones y documentos producidos por organizaciones libertarias de Argentina, Cuba, México y Uruguay entre 1960 y 1962.

Palabra clave: anarquismo - Revolución cubana - Movimiento Libertario Cubano en el Exilio - Federación Anarquista Uruguaya

Abstract: Sixty years after its triumph, the Cuban Revolution continues to provoke passionate debates about its significance and realities, as it sparked the hope of a deep change in the fates of the American peoples. However, a left-wing family questioned it in its very origins, noting, very early on, the dangerous turn

DOI: https://doi.org/10.46688/ahmoi.n20.349

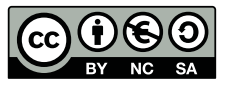

Obra bajo licencia Creative Commons 4.0 International (Atribución - NoComercial - Compartirlgual) 
taken towards Soviet-style socialism. This article examines how the anarchists reacted and interpreted this process. The analysis draw on different publications and documents produced by libertarian organizations in Argentina, Cuba, Mexico and Uruguay between 1960 and 1962.

Keywords: Anarchism - Cuban Revolution - Movimiento Libertario Cubano en el Exilio - Federación Anarquista Uruguaya

Recepción: 30 de noviembre de 2021. Aceptación: 12 de febrero de 2022.

$$
* * *
$$

\section{Introducción}

En la primavera de 1960 el prestigiado anarquista alemán Augustin Souchy aterrizó en la mayor de las Antillas. Tan pronto como descendió del avión, quien fungiera como secretario de relaciones exteriores de la Federación Anarquista Ibérica (FAI) durante la guerra civil en España, emprendió un recorrido por la Cuba revolucionaria con el propósito de estudiar sus logros, valorar la reforma agraria y hacer sugerencias al gobierno a fin de mejorar su implementación. La estancia de Souchy en la isla obedeció a una invitación expresa de los revolucionarios isleños, pues el nacido en Racibórz era una autoridad en los estudios agrarios y la organización socialista del campo.

Durante su visita, Souchy conoció cooperativas, ciudades, campos, escuelas, espacios de recreación, industrias en construcción. Habló con obreros, guajiros, autoridades, militares y, por supuesto, con anarquistas. De sus observaciones escribió "Estudios sobre cooperativismo y colectivización en México, Israel, España y Cuba”, trabajo que se insertó dentro de la obra Cooperativismo y colectivismo, coordinada por el entonces director del Instituto Nacional de Reforma Agraria (INRA), Antonio Núñez Jiménez, y aparecida bajo el sello Lex, propiedad del exabogado de la Confederación Nacional del Trabajo (CNT), Mariano Sánchez Roca. La obra de Augustin, empero, fue mutilada y reconfeccionada por Roca a fin de no enemistarse con Castro, pues Souchy era bastante duro con el modelo agrario emprendido por los cubanos. Por ello, Roca decidió suprimir todo aspecto crítico y dio al ensayo un cariz periodístico, ante tal acto el alemán decidió remitir su original a Argentina para publicarse integro en la revista Reconstruir. ${ }^{1}$

1. Souchy le escribió a Jacobo Prince que su escrito, tal como se editó en Cuba, daba la impresión de ser un apoyo a la Revolución, cuando él dejó patentado que "el gobierno de Castro era cien por ciento dictatorial y todas sus medidas eran absolutamente estatales. Ha instalado en Cuba un capitalismo estatal que no es mejor, sino peor, bastante peor, que el capitalismo privado", "Carta de Souchy a la Federación Libertaria 
A lo antes citado, y como parte de una campaña de esclarecimiento sobre la cuestión cubana, la editorial Reconstruir publicó, a fines de 1960 , la obra de Souchy, ${ }^{2}$ convirtiéndose en uno de los primeros análisis, desde el anarquismo, del proceso cubano. A ese documento pronto se sumaron los testimonios de los libertarios cubanos, como el de Abelardo Iglesias (1963), ${ }^{3}$ Casto Moscú y Jesús Diéguez. ${ }^{4}$ Los cuales inauguraron un breve, pero áspero debate en el seno del anarquismo respecto al significado y proyección de la Revolución, a la cual defendieron, apoyaron y legitimaron, pues en ella cifraron sus esperanzas e incluso llegaron a imaginar que era el inicio de la revolución latinoamericana.

En esa arista, entre 1955 y 1960, los anarquistas cedieron espacio en sus publicaciones para dar a conocer la heroica batalla encabezada por los barbudos de la sierra, pero no sólo eso, organizaron eventos para denunciar al batistato y orientaron sus organismos, como la Juventud Antifranquista Española en México, a levantar campañas de recolección de fondos pro Revolución cubana. ${ }^{5}$ Así, en el arco temporal citado, a Castro se le calificó, desde el anarquismo, como un hombre sincero, noble, democrático, justo, incorruptible y leal. Era el líder que Cuba necesitaba para encaminarse a un régimen democrático marcado por un profundo liberalismo social, capaz de romper con el tutelaje e intervencionismo norteamericano.

Esa lectura partió de su conocimiento del contexto internacional, imbuido en la Guerra Fría con su feroz anticomunismo, motivo suficiente para que los libertarios reconocieran las limitaciones impuestas al proceso cubano, de ahí que sus esperanzas se compendiaran en el advenimiento y consolidación de una democracia liberal. A su parecer, si los revolucionarios no peregrinaban por ese sendero corrían dos riesgos: el primero conocido por todos tras los recientes acontecimientos en Guatemala y, el segundo, más temible, el injerencismo de la "República de los soviets".

Argentina (FLA)", 24 de noviembre de 1960, archivo del Centro de Documentación Libertaria Jacobo Prince de la FLA (CDLJP/FLA).

2. La Asociación Libertaria de Cuba Editorial también divulgó una parte del estudio bajo el nombre Cooperativas libres.

3. El texto de Iglesias apareció, originalmente, en el periódico de los anarquistas italoamericanos: Abel, "Rivoluzione e dittatura...", L'Adunata dei Refrattari, $\mathrm{n}^{\circ}$ 44, 4 de noviembre de 1961, p. 3; luego en Reconstruir y, en 1963, en folleto: Iglesias, "Revolución y dictadura", Reconstruir, n 18, mayo-junio de 1962, pp. 10-18.

4. Su valoración salió en el impreso Tierra y Libertad; Casto Moscú, "La contrarrevolución marxista...", Tierra y Libertad, n² 231, agosto de 1962, p. 26.

5. Hernández, "Vigorosa protesta...", Juventudes Españolas Antifranquistas, especial, s/f, p. 2. 
Bajo esos parámetros este texto, que he dividido en diversos apartados, está articulado en tres grandes temas. Primero me encaminé a evidenciar la respuesta de los libertarios cubanos ante lo que ellos consideraron una deriva de "su" revolución; en un segundo momento me centré en dilucidar cómo el anarquismo continental recibió y respondió a la "sovietización" de la Revolución; y, en un tercer anclaje, me adentré a conocer los debates producidos en el seno del anarquismo en torno a la Revolución, en particular a la discusión entre los anarquistas cubanos, mexicanos y argentinos con sus pares uruguayos.

\section{Un panorama del anarquismo}

Con la apertura de la década de 1930, el movimiento libertario en América Latina comenzó su declive. Este fenómeno se derivó de varios factores, en primera, por el ascenso de gobiernos dictatoriales o sumamente autoritarios con tintes populistas. Un motivo adyacente fue la consolidación de los partidos comunistas bajo el amparo y prestigio de la Unión Soviética, quienes se dieron a la tarea de ocupar los espacios que el anarquismo fue abandonando; otro aspecto lo patrocinó la incapacidad de algunos sectores del anarquismo para actualizar sus líneas de organización, acción y pensamiento, impidiéndoles responder adecuadamente a los acelerados cambios culturales y económicos. Los puntos acotados, tesis manejada parcialmente por Rama y Cappelletti (1990, p. XIII), explicarian en gran medida el decaimiento del anarquismo. Haciéndose particularmente grave en Argentina, Cuba y México, regiones donde poseyó grandes bases sociales.

Aunado, se debe advertir que el anarquismo y todo movimiento político y social, desarrollado en la segunda posguerra, se inscribió en la dinámica de la Guerra Fría, en particular en su batalla en el campo intelectual y cultural. Con todo, como lo hacen notar Glondys (2012) e Iber (2015), en América Latina ese conflicto no fue tan intenso como en Europa por dos factores, el primero: el dominio casi "congénito" de los Estados Unidos sobre América Latina, y, segundo, por la errática estrategia del Congreso por la Libertad de la Cultura y su publicación destinada al continente: Cuadernos.

Por otra parte, es forzoso remarcar que el anticomunismo y antitotalitarismo anarquista ostentaba una raíz más profunda que el practicado y profesado por las democracias occidentales y el utilizado como ariete por el Congreso y sus publicaciones contra los soviéticos. Oportuno es aclarar, igual, que el anticomunismo proferido por los grupos ácratas latinoamericanos, en este periodo histórico, obedeció a una estrategia discursiva para sortear la represión cernida contra todo aquello que fuera, o pareciera, comunista. En esencia, los libertarios se reivindica- 
ban como comunistas, pero ante una posible confusión, persecución y censura, optaron por suprimirlo de sus publicaciones y organizaciones e incluso, en algunos casos, enunciaron un anticomunismo recalcitrante, pero este se debe entender más como un antisovietismo. ${ }^{6}$

Por tal, si el discurso de las publicaciones financiadas por los norteamericanos, como Cuadernos, se asemejó al blandido por los anarquistas, estos no fueron menos suaves en sus denostaciones contra el imperialismo norteamericano o contra las democracias, a las cuales también fustigaron como totalitaristas. Pese a ello, ciertos libertarios con gran prestigio colaboraron, sin saberlo al parecer, en las revistas político-culturales subvencionadas por la Agencia Central de Inteligencia (CIA). Como fue el caso del prolífico escritor Louis Mercier-Vega (Santiago Parane), Campio Carpio o Benito Milla. ${ }^{7}$

En ese ambiente estalló el proceso revolucionario cubano, en el cual se involucraron anarquistas isleños y continentales, entre ellos Octavio Alberola quien entrenó con los guerrilleros cubanos en México e impulsó campañas a favor de la Revolución. Entonces, aunque disminuido y debilitado el anarquismo participó de una u otra manera, dentro y fuera de Cuba, en el proceso armado, debatió a profundidad su significado y sus proyecciones. Mas, al darse los primeros visos de una transición al

6. Por lo menos hasta 1917 los anarquistas habian "monopolizado" el uso del término comunismo; mas a partir de 1920 se dieron varias disputas en su seno por la pertinencia de utilizar o no el vocablo. Ejemplifico con el caso argentino, el cual es más dramático, pues desde sus orígenes todos los anarquistas se consideraron comunistas, desde los antiorganizadores, como El Perseguido, hasta los finalistas de la FORA en su V Congreso, situación que se mantendria más o menos estable hasta 1930, cuando surge la polémica sobre el término. E.g., en el congreso fundacional de la Federación Anarco-Comunista Argentina (FACA), diversas voces se pronunciaron por no llamarse comunista; la local de Pergamino pidió asentar en actas su disconformidad, aduciendo que no todos los anarquistas eran comunistas, "Actas del CC de la FACA", noviembre de1935, CDLJP/FLA. En los congresos subsecuentes a su fundación, se debatiria la idoneidad de cambiar el nombre por el "desprestigio" y el temor a ser "confundidos" con los bolcheviques, pero ello sólo acaecería en su IV congreso, en 1955. Representativo de la estrategia discursiva anticomunista lo alumbra Acción Libertaria cuando le fue retirada la tarifa reducida y el franqueo pagado, por "hallarse comprendida dentro del decreto 4965/59, medida [para] reprimir y combatir actividades totalitarias, comunistas, peronistas y antidemocráticas", en respuesta a ello la FLA señaló que al parecer no conocian la naturaleza ni la historia de la FLA, la cual a casi 25 años de actividades "profesa y sustenta las ideas del socialismo libertario, ha desarrollado y posee una trayectoria de neta y rotunda oposición antitotalitaria, anticomunista y antiperonista, documentada en múltiples publicaciones y documentos", "Carta de la FLA al Correo Central", 5 de diciembre de 1960, CDLJP/FLA.

7. Las sospechas sobre Mercier, de trabajar para la Central, eran grandes, incluso Federica Montseny lo acusó de ser uno de sus agentes (Glondys, 2012, p. 316). Al revisar los índices de Cuadernos se observa su participación. 
marxismo-leninismo no dudaron en interpretarla y cuestionarla desde su campo intelectual y sus premisas ideológicas, sin que ello significara estar en concomitancia con el imperialismo "yanqui".

Para cerrar este apartado, conviene recordar que uno de los pilares del anarquismo ha sido su internacionalismo. El acratismo se ha constituido en el único movimiento que ha logrado mantener una red de relaciones y apoyos sin la necesidad de un organismo centralizado ni supranacional que dirija o encauce la acción o la "idea". A través de su historia diferentes geografias se han trazado como nodos receptores-emisores de solidaridad. En la mayoría de los casos materializada en el envío de dinero para socorrer a presos, enfermos o fallecidos, o a familiares de estos, campañas de agitación con el objeto de salvarlos de la muerte, del presidio o como centros de organización, conspiración o refugio. En esa lógica se insertó la Revolución cubana, donde los periódicos tejieron una red de apoyo, debate y reflexión sobre su significado, sus proyecciones y sus consecuencias. De ahí que, una vez proclamado su carácter socialista, desde las organizaciones e impresos ácratas, se convocó a hermanar esfuerzos en defensa de sus compañeros cubanos, invitando a toda la militancia a denunciar lo que ellos consideraron una deriva de la Revolución y un peligro sobre el continente por la infiltración soviética.

\section{Contexto}

En enero de 1960 la Asociación Libertaria de Cuba (ALC) celebró un pleno con el propósito de valorar "su" revolución, dibujar su posición frente a quienes detentaban el poder y trazar una línea de acción acorde a las circunstancias impuestas por el tono nacionalista, centralizador y autoritario adquirido por el gobierno emanado de la lucha armada. Los acuerdos de la reunión se publicaron en julio de aquel año con el título Declaración de principios de la Agrupación Sindicalista Libertaria (1960). En el folleto se planteó que, para una transformación real en las estructuras de cualquier sociedad, era indispensable proceder simultáneamente contra el binomio Estado/capital, es decir, emprender el cambio del modelo económico junto a la disolución del Estado como entidad política y administrativa, sustituyéndolo en sus funciones con organismos revolucionarios y populares como los sindicatos, municipios libres, cooperativas agrarias e industriales autónomas y colectividades campesinas libres de mediaciones, gubernamentales o privadas (ASL, 1960).

Paralelo a la edición de la Declaración los ácratas cubanos, en alianza con otras fuerzas de izquierda, constituyeron el Movimiento de Acción Sindical (MAS), que se presentó como un organismo revolucionario de la 
clase trabajadora y enarboló los postulados de la justicia social. Para el MAS, la Revolución condujo a los trabajadores, y a sus organizaciones, a condiciones de sometimiento y entreguismo como en los peores tiempos, en lugar de emanciparlos, a causa de obligarles a renunciar a sus preciadas conquistas y vedarles el derecho a luchar por mejoras inmediatas. ${ }^{8}$ La oposición del MAS a la Revolución hecha gobierno les ganó bien pronto enemigos, el principal, al que catalogaron como "aristocracia revolucionaria", por ello su actuación debió ondear entre la legalidad y la clandestinidad. En esa dinámica editó, de forma clandestina, su órgano de difusión: Nuestra Palabra Semanal (NPS), el cual fue remitido a sus principales núcleos, el más importante de ellos asentado en Nueva York, sitio donde se reimprimía y giraba a las federaciones anarquistas con la finalidad de enterarlas de la cuestión cubana.

A ese respecto, tanto el MAS como la ALC compartieron presupuestos básicos en torno a la superación del régimen capitalista, amparados en la concepción ácrata de valerse de los sindicatos como vértebra económica de la nueva sociedad. Sustentaban que la revolución social debía garantizar el disfrute de derechos básicos como "la libertad de expresión, pensamiento y petición, el derecho al trabajo, a una vida digna, a la inviolabilidad del domicilio, a ser juzgado imparcialmente, a la cultura y a la salud", tender a eliminar la discriminación racial, las persecuciones políticas, la intolerancia religiosa y la injusticia (ASL, 1960).

\section{La situación}

Con el acelerado proceso de estatización y centralización económica, política y cultural, los libertarios cubanos perdieron la esperanza de un golpe de timón en el destino de su terruño, al cual caracterizaron como un socialismo de Estado y tan o más represivo que el recién derruido batistato. En ese panorama, los ácratas emprendieron dos caminos con el fin de defender y reencauzar "su" revolución. Por una parte, privilegiaron la denuncia por medio de informes anónimos e impresos salidos desde Cuba y cartas y boletines remitidos, desde su exilio en Estados Unidos, al movimiento ácrata internacional. En ese primer plano alertaban a los pueblos americanos sobre el riesgo de la instauración de un régimen al estilo soviético en Cuba, pues ello derivaria, inevitablemente, en la agudización de la represión ejercida por los Estados latinoamericanos so pretexto de contención del comunismo, otro peligro sería identificar las aspiraciones populares de libertad y justicia con la voluntad de ser de un Estado, donde lo ausente era precisamente la libertad.

Otra vía de acción, a la que acudieron los anarquistas isleños nu-

8. "Prólogo", NPS, n 1, 13 de junio de 1960, p. 1. 
cleados en torno a la Asociación Libertaria de Cuba y al sector gastronómico, fue participar en la lucha armada en coalición con otros grupos opositores al castrismo. Esa última acción les redundó en un fracaso total ante la falta de cohesión de los sectores rebeldes, tanto por la diversidad de posturas como la ausencia de objetivos comunes, esto impidió el bosquejo de un programa mínimo de acción y de medidas a proseguir en caso de triunfo. Dos consecuencias inmediatas de esta estrategia fue, primero, "legitimar" al Estado policíaco levantado por el grupo vencedor; y, segundo, la represión desencadenada desarticuló toda oposición semilegalizada y clandestina dentro de la Isla. ${ }^{9}$

En otro orden de ideas, durante 1959 y 1960, en el continente, Cuba representó varios dilemas por la falta de información verificable y merecedora de confianza. Ello propició enconados debates sobre si la Revolución era un movimiento liberador o un malogrado intento de fundar una Cuba justa, igualitaria y libre. Esto tuvo su origen en que los impresos libertarios cubanos, que llegaban a los anarquistas del continente, no denunciaban nada puntual, sólo generalizaciones y mensajes entre lineas que pocos sabian leer. ${ }^{10}$

Esta nebulosidad se disipó a partir de la remisión de una carta de la Asociación Libertaria de Cuba (ALC), fechada en septiembre de 1959, a la Comisión Internacional Anarquista (BCIA), la cual se publicó en mayo de 1960 en el Bulletin CIA. En la misiva los cubanos patentaron su aprecio y defensa de las medidas benéficas para el proletariado cubano emprendidas por la Revolución, aunque fueran un simple reformismo y no una profunda transformación de las bases del capitalismo o del Estado. Su preocupación, en cambio, se fundó en el control cada vez mayor, por parte del Estado, de todas las actividades políticas, económicas, sociales, culturales y recreativas. Los cubanos destacaron que si no atacaban la situación, como se merecía, era por las consecuencias resultantes: represión y contribuir a la campaña de las fuerzas reaccionarias, capitalizadoras de todo ataque a la Revolución a fin de respal-

9. Prince, “Cuba y los ideólogos...”, Acción Libertaria, n 172, julio de 1961, p. 3.

10. Iglesias le escribió a Prince: "[Les enviaremos] literatura circulante, preferentemente la oficial, para que tengan elementos de juicio para interpretar los hechos correcta e imparcialmente, ustedes que son perros viejos sabrán interpretar los textos y los hechos ahorrándonos a nosotros el tener que hacerlo en una correspondencia postal que seguramente está controlada, lean con mucho cuidado las cartas que les enviaremos en el futuro, pues tendremos que utilizar frecuentemente giros simbóli$\cos$ y frases en doble sentido. Todas las preocupaciones reflejadas en tus palabras están perfectamente justificadas", "Carta de Iglesias a Prince", CDLJP/FLA, 9 de agosto de 1960 . 
dar una intervención sobre Cuba. Circunstancias que los empujaron a calibrar sus críticas y a disuadirlos de remitir análisis detallados. ${ }^{11}$

A poco de aparecer la carta, la Federación Libertaria Argentina (FLA), la Federación Anarquista Mexicana (FAM), la Liga Libertaria de los Estados Unidos y la Federación Anarquista Uruguaya (FAU), comenzaron a recibir informes confidenciales desde la isla signados por Antonio Rueda. Gracias a este informante se conoció de primera mano y, para ellos, de manera veraz lo acontecido en Cuba. En sus informes Antonio Rueda explicó el proceso de estatización, el centralismo político y las decisiones erradas, desde su posición, en materia económica implementada por la "oligarquía revolucionaria", las cuales condujeron al pueblo cubano a una situación desesperante. En una de sus descripciones el confidente señaló que los anarquistas eran sabedores de lo que era un Estado totalitario y de cómo funciona, en dónde se enderezaba una economía de Estado y un sistema político policíaco. Eso era Cuba, remarcó el Antonio, pues los llamados tribunales revolucionarios funcionaban a capricho, se condenaba a largas condenas o a muerte sin pruebas, se acusaba de conspirar o propagar el anticomunismo. También detalló haber sido testigo del ametrallamiento de un grupo de personas por el "delito" de pretender evadirse del país clandestinamente, en una embarcación rudimentaria. ${ }^{12}$

\section{Fusilados, encarcelados, exiliados}

Gracias a Antonio Rueda fue que se conoció a detalle la suerte de los anarquistas recluidos en las ergástulas de la Revolución, a los caídos en el paredón o quienes desesperadamente buscaban salir de la isla. ${ }^{13} \mathrm{El}$ padecimiento de los libertarios encarcelados, entre quienes se hallaban Isidro Moscú, Luis Miguel Lisuaín, Antonio Dagas y José Aceña, ${ }^{14}$ alarmó profundamente a los ácratas, pues en general a los presos políticos se les negaba la visita regular, el envío de alimentos y, cuando estos se admitían, eran robados. Tampoco se permitía pasar medicina, siendo norma que la mayoría de los reclusos estaban enfermos por el hacinamiento, la falta de higiene y las continuas torturas, fisicas y sicológicas. ${ }^{15}$

Las narraciones de Antonio Rueda, relacionadas con la situación

11. "Asociación Libertaria de Cuba", BCIA, $\mathrm{n}^{\circ} 4$, mayo de 1960 , p. 8.

12. Antonio, "Información del interior n 10", CDLJP/FLA, 25 de enero de 1962.

13. "Al movimiento libertario", Tierra y Libertad, n² 221, septiembre de 1961, p. 4.

14. El proceso seguido a estos ácratas puede consultarse en un informe presentado ante la Organización Internacional del Trabajo, "Casos de Libertad Sindical. Informe $\mathrm{n}^{\circ}$ 103. Caso 425", disponible en: https:// bit.ly/33A2WbZ.

15. "Pueblos de América, jalerta!", Regeneración, n 69-70, mayo-junio de 1962, p. 3. 
de los presos, perseguidos y fusilados, fueron confirmadas con los testimonios de quienes lograron abandonar la Isla, por ejemplo, una entrevista a Jesús Diéguez publicada en Views and Comment, órgano de la Liga Libertaria norteamericana, permitió al anarquismo ver una pincelada de lo acontecido en Cuba, en especial de los aparatos represivos del castrismo.

Diéguez estimó que a fines de 1960 habian salido de Cuba entre 20 y 30 ácratas, y, para conseguirlo, hicieron frente al temible G2, encabezado por Ramiro Valdés, integrado con cerca de mil elementos en La Habana y con cientos de "chivatos" desperdigados en todos los rincones de Cuba. Evadieron, igualmente, a los nefandos Comités de Defensa de la Revolución (CDR) organizados "en cada rincón del país, cuya misión específica es la de fomentar la confidencia política y denunciar a toda persona que se atreva a expresar, o sea sospechoso de discrepancia con el gobierno castrista". ${ }^{16}$ Este relato fue reafirmado por el anarquista ibérico exiliado en Cuba, Salvador García, quien al referirse al ambiente enrarecido por los "soplones", comentó:

Terminaron las reuniones de afines en ideología e, incluso, de hermanos en desgracia. El sentimiento de amistad y camaradería desaparece. Surge por doquier el recelo y la desconfianza. Terminan las pláticas francas con los vecinos, y hasta con amigos y familiares. El círculo de los intimos se reduce hasta su extinción. Uno se aísla, buscando la seguridad en la soledad. ${ }^{17}$

Además de la pena corporal aplicada a ciertos anarquistas, por discrepar del camino adoptado por la Revolución, a otros se les fusiló, entre ellos a Augusto Sánchez, un niño campesino de 17 años, ejecutado en la provincia de Pinar del Río. ${ }^{18}$ A los libertarios fusilados y en reclusión, se les sumaron aquellos que se vieron obligados a evadirse de la isla a través del asilo. Al igual que cientos de cubanos, los anarquistas se acercaron a las sedes diplomáticas de los países latinoamericanos con la esperanza de marcharse de Cuba, su situación, por supuesto, no fue más halagüeña que la de los presidiarios. Salvador García, Casto Moscú, López del Rincón, Saiz Mora y Sánchez Roca eligieron ese camino.

La historia de Roca representa la tragedia de muchos anarquistas ibé-

16. Finch, "Una entrevista...", Reconstruir, n 14, septiembre-octubre de 1961, p. 28. Diéguez, junto a Emilio Tró, encabezó la Unión Insurreccional Revolucionaria (UIR), grupo bandidista social al que perteneció brevemente Fidel Castro.

17. Miró, "En torno a la Revolución cubana", Comunidad Ibérica, n 5 , julio-agosto de 1963, p. 24.

18. "Más fusilados", $B I L, \mathrm{n}^{\circ} 7$, septiembre-diciembre de 1962, p. 3. 
ricos exiliados, o simpatizantes de estos, quienes escapando del régimen franquista recalaron en paises bajo dictaduras no menos sangrientas que la implementada por Francisco Franco. Roca se avecinó en Cuba tras el triunfo de los nacionalistas españoles. En la "perla de las Antillas" fundó la editorial Lex, editó las obras completas de Rómulo Gallegos y de Martí, convirtiéndose en un puntal de los barbudos en los días de Sierra Maestra y en los primeros meses de la Revolución; mas, al poco, Fidel Castro lo catalogó como reaccionario, su editorial fue intervenida y él obligado a asilarse en la embajada venezolana, donde permaneció 42 dias (Domingo, 2009, p. 507). ${ }^{19}$

A las formas "ilegales" de escapar de Cuba, se sumó una vía legal a través de un requerimiento al gobierno. Alternativa clausurada a partir de octubre de 1960 cuando se inició la primera etapa del bloqueo norteamericano. En ese momento existían en las estaciones de policía más de 200 mil solicitudes. Quienes emprendieron el exilio por ese método debieron presentar una petición acompañada de una renuncia escrita al empleo, un inventario completo de bienes personales, incluyendo utensilios caseros. Estas declaraciones eran verificadas por los CDR de las respectivas barriadas y, desde ese instante, el peticionario era declarado contrarrevolucionario y sometido a estrecha vigilancia, perdiendo en automático todo derecho. ${ }^{20}$

Con la situación tornada día a día más peligrosa por su calidad de opositores, al mediar 1960 los ácratas con mayor responsabilidad habían emprendido el exilio, pero derivado de los eventos de playa Girón y tras la detención, por una "confusión", de por lo menos una docena de ellos, el grueso de la militancia optó por el destierro.

Por lo anterior, los nuevos espacios de los libertarios cubanos se tejieron en el lugar geográfico que históricamente ha servido de refugio y conspiración a todos los revolucionarios cubanos: la costa Este de los Estados Unidos. En esa cartografia se organizaron dos grupos. El primero surgió al mediar 1960 bajo el nombre de Grupo Libertario Cubano de Nueva York (GLCNY), compuesto por trabajadores gastronómicos vinculados al sector gastronómico libertario y al Movimiento de Acción Sindical. A finales de 1960 nació el segundo polo en Florida, con el nombre de Movimiento Libertario Cubano en el Exilio. En enero de 1961 estos núcleos convocaron a un cónclave al que acudieron ácratas exiliados en Estados Unidos, Puerto Rico, Venezuela y Honduras,

19. Víctor García, "La situación de Cuba", Tierra y Libertad, n 220, agosto de 1961, p. 4.

20. Miró, "En torno a la Revolución cubana", Comunidad Ibérica, $\mathrm{n}^{\circ} 5$, julio-agosto de 1963, pp. 23-27. 
fundándose la Delegación General del Movimiento Libertario Cubano en el Exilio (MLCE).

Al comenzar sus tareas, el MLCE reconoció sus yerros comunicativos al no brindar información clara, expedita, precisa y merecedora de confianza para el grueso del movimiento anarquista, una consecuencia de esa errática comunicación derivó en la "incomprensión de algunos núcleos libertarios respecto a la tremenda tragedia cubana". ${ }^{21}$ Otro resultado bastante perjudicial fue sembrar una confusión entre la militancia del continente, la cual interpretó como censura la desaparición de los impresos Solidaridad Gastronómica y El Libertario. ${ }^{22}$ Por esa razón el Movimiento resolvió editar el Boletín "con objeto de ofrecer datos e informaciones sobre Cuba, perfectamente controlados y verificados", la publicación fue de carácter interno para evitar discusiones sobre "interpretaciones de los hechos". ${ }^{23}$

De ese modo, y una vez en la "seguridad" del exilio, los anarquistas cubanos llamaron a todas las fuerzas revolucionarias a emprender una batalla total contra el castrismo, para reconquistar la libertad y el derecho del pueblo cubano a ser libre y continuar su obra emancipatoria de acuerdo a sus intereses e idiosincrasia, sin la imposición de ninguno de los dos imperialismos. Es importante tener esto presente, pues los ácratas en todo momento se posicionaron por la prosecución de la Revolución, ni parar ni dar marcha atrás a las medidas de neto contenido popular, es decir, no apostaron ni toleraron las embestidas militares al estilo de bahía de Cochinos, al contrario, anhelaban un cambio de rumbo por medio de una profundización revolucionaria. ${ }^{24}$

21. "Porqué publicamos este Boletín", BIL, $\mathrm{n}^{\circ}$ 1, febrero de 1962, p. 1.

22. Debido a la información "falsa" dada a luz, los cubanos "reprendieron" a sus compañeros continentales por malinformar sobre su situación, atrayéndoles sobre sí a los aparatos represivos, ante ello recomendaron redactar, todo lo relacionado con Cuba, a manera de no ofrecer intimidades del movimiento "ya que gran cantidad de cartas llegan abiertas", conminaron a comprobar la información antes de publicarla "para no incurrir en falsedades como la publicada acerca de una supuesta prohibición de El Libertario y Solidaridad Gastronómica", "Circular extraordinaria de la ALC", CDLJP/FLA, 15 de enero de 1961.

23. "Porqué publicamos este Boletín", BIL, $\mathrm{n}^{\circ} 1$, febrero de 1962, p. 1.

24. "Nuestra Palabra", $B I L, n^{\circ} 3$, julio de 1962, p. 1. En una carta los cubanos dejan bien en claro el asunto: "Únicamente la estupidez de los señores de la CIA creyeron que tumbarían a Castro con ella, nosotros repudiamos todo tipo de intervención en Cuba por estos elementos que, a lo que van, es a expoliar al pueblo cubano y a quitarle todas las conquistas de utilidad logradas en la revolución, traicionada por Castro, estamos muy esperanzados con los acontecimientos últimos en Cuba, donde se ha manifestado públicamente el pueblo en contra de la barbarie comunista, por esta causa ha habido muertos y heridos, pero son sintomas que nos alientan a seguir en 
En esa linea y para cumplir con sus objetivos apremiantes, los cuales descansaban en sacar a sus compañeros y familiares de Cuba o cubrir sus necesidades perentorias dentro de la Isla, el MLCE instó a "sus hermanos de ideas" a concurrir en su ayuda. A ese fin, en la República del Plata, se reactivó la Solidaridad Anarquista Internacional (SAI), convirtiéndose en la primera organización en auxiliar a los cubanos. Poco después, a petición de SAI y del MLCE, se impulsó la creación de una Comisión coordinadora pro ayuda a los libertarios cubanos, con el propósito de centralizar y administrar las aportaciones, sugiriéndose como sede a México. ${ }^{25}$

\section{Querellas}

A pesar de las denuncias, sectores del anarquismo continental recelaron de la veracidad de la información remitida por los cubanos, por eso la CNT comisionó a un delegado a la isla, con la intención de despejar sus dudas y tomar las medidas acordes a las circunstancias objetivas. Para el efecto se designó a Joaquín Cortés, quien aterrizó en Cuba al mediar 1961 y fue recibido por Manuel Gaona, dirigente de una facción escisionada de la ALC, adepta al castrismo.

Como resultado de su visita, Cortés elaboró un escueto informe que leyó a los núcleos anarquistas de México en agosto de 1961. El balance era demoledor: desmontaba todas las denuncias del MLCE, desestimaba las denuncias de Antonio Rueda y las acusaciones del Movimiento de Acción Sindical. En primer término, Cortés apuntó que "antes del triunfo del actual régimen no llegaban a cien los efectivos de la ALC", que el movimiento se reducía a una docena de anarquistas defendiendo a Castro. Negó la persecución, encarcelamiento y asesinato de libertarios, al contrario, aseveró que toda la prensa ácrata circulaba sin problemas. Agregado a ello, Cortés subrayó que se le había comunicado que el peligro cernido sobre el "moribundo" movimiento libertario cubano era resultado de su actuación al lado de los contrarrevolucionarios. Empero, sobre este punto, Cortés notificó que, debido a la confusión reinante en los días de la invasión, el secretario de la CNT y ocho anarquistas más fueron detenidos a pesar de no tener ninguna relación con los grupos mercenarios. Salvo ese "malentendido", Cortés destacó que cualquiera podía conspirar y hablar contra Fidel Castro, luego, en contradicción, puntualizó que el gobierno edificó "cierta mística revolucionaria, ha convertido a la inmensa mayoria de los ciudadanos en soplones, se entera

nuestra lucha por la continuación de la revolución", "Carta del GLCNY a la FLA", 16 de julio de 1961, CDLJP/FLA.

25. "Circular s/n de SAI", CDLJP/FLA, agosto de 1961. 
de todos los movimientos de los inquilinos de las casas". Sumado a esa "mística", Cortés levantó más suspicacias sobre la realidad cubana al señalar que las autoridades revolucionarias afirmaban que los cenetistas tenían la libertad de salir de Cuba, por supuesto, pero mediante lista. Para cerrar su valoración sobre el asunto, Cortés instó a no dar nada de dinero a los mentados organismos de ayuda a los anarquistas cubanos y sus familias. ${ }^{26}$

El informe Cortés produjo una honda conmoción dentro de los núcleos anarquistas y motivó una profunda reflexión, pero se le dio una respuesta unánime: se le calificó de deleznable. El MLCE declaró que, ante las calumnias vertidas por Cortés, tenian una buena cantidad de datos y documentos probatorios de todo cuanto afirmaba, sosteniendo que el delegado de la CNT fue víctima de una "zancadilla de los tres o cuatro exmilitantes libertarios que, olvidando sus principios, se vendieron por el clásico plato de lentejas a la dictadura totalitaria castro-comunista". Acusando a Cortés de "fragilidad ideológica y endeblez moral", reiterando su propósito de aclarar todo lo referente a la "conducta honesta y valerosa de sus compañeros durante los siete años de ignominia del batistato y los dos años y medio del bolche-fidelato". ${ }^{27}$

Por lo "lamentable" del informe, los anarquistas radicados en México se vieron condicionados a aceptar la propuesta de SAI-MLCE y se hicieron cargo de la Comisión Coordinadora de Solidaridad con el Movimiento Libertario Cubano, quedando su secretariado en manos del sector de la CNT encabezado por Fidel Miró. ${ }^{28}$

Pertinente es precisar que, a decir del MLCE, la división en su seno, ocurrida a principios de 1960, se redujo a "tres o cuatro viejos militantes [encabezados por Gaona], que mantuvieron la tesis del apoyo incondicional a Castro"; manifestando que el movimiento libertario cubano, representado por la CNT de España en el exilio en Cuba, la ALC y el sector gastronómico, estaban en sintonía en su oposición al castrismo, por ello solicitaron al movimiento internacional no hacer "maromas dialécticas sobre un hecho inexistente", es decir, sobre su postura contra el nuevo régimen. ${ }^{29}$

26. "Texto nota de Tierra y Libertad", CDLJP/FLA, 23 de agosto de 1961.

27. "Carta del MLCE a la FLA", CDLJP/FLA, 18 de septiembre de 1961.

28. "Carta del MLCE a la FLA", CDLJP/FLA, 18 de septiembre de 1961.

29. "Carta del MLCE a la FAU", CDLJP/FLA, 24 de agosto de 1961. Si bien no se conoce cuál fue la postura y las postreras acciones de los anarquistas adheridos al castrismo, por la falta de documentos, un artículo de Gaona, aparecido en los prolegómenos de la extinción de El Libertario, da indicios para afirmar que abandonaron el anarquismo, Gaona Sousa, "Como veo la Revolución cubana", El Libertario, $\mathrm{n}^{\circ} 10$, 31 de mayo de 1960, p. 1. 
Es importante resaltar lo antes escrito, toda vez que Frank Fernández toma como valedero y de grandes y funestas repercusiones un documento lanzado por Gaona con el título Una aclaración y una declaración de los libertarios cubanos, fechado y firmado en Marianao en noviembre de 1961. Asume Fernández que el documento se difundió con el "propósito de difamar a los libertarios que no coincidian con la devoción revolucionaria" de los anarco-castristas (Fernández, 2000, pp. 98).

Sin embargo, Una aclaración es una respuesta a la creación de la Comisión coordinadora, pues la misma comienza por apuntar sobre una "colecta de dineros para los presos libertarios cubanos, para sacar del país a los perseguidos y sus familias". Aparte, en Una aclaración se repite letra a letra el informe brindado por Cortés, se afirmó que no existía ningún anarquista preso o perseguido, se testificaba que la totalidad de anarquistas cubanos se integraron a los organismos revolucionarios, pues sus aspiraciones eran cumplidas por la Revolución. ${ }^{30}$

Fernández sostiene que el documento Gaona, como él lo bautizó, circuló "en casi todos los medios anarquistas a que tenían acceso sus autores, de este modo crearon la confusión primero y la duda después con relación al MLCE" (Fernández, 2000, p. 108). Al margen de esas afirmaciones, ese documento de "siniestras consecuencias" no lo he localizado en ningún archivo, menos aún en la prensa analizada, por ello surge la duda, genuina, de su verdadera difusión y, más aún, permite cuestionar la conclusión a que arriba Fernández sobre una supuesta orfandad de los anarquistas cubanos en el exilio a partir de su emisión. Esto último no se sostiene, en primera, porque el documento Gaona es posterior a la fundación de la Comisión; segundo, en los balances financieros se aprecia la ayuda que recibieron, de dónde provino y en qué se gastaron los recursos colectados durante un año en solidaridad con los anarquistas cubanos. ${ }^{31}$

\section{La Federación Anarquista Uruguaya}

En agosto de 1960 una delegación de la FAU, con Gerardo Gatti a la cabeza, visitó la ciudad de Buenos Aires. Su presencia motivó a los redactores de La Protesta y a la FLA a improvisar una conversación sobre Cuba. Esta se articuló sobre dos posiciones, de un lado la FAU orientó sus argumentos en considerar a la Revolución como un proceso positivo. Los argentinos, en contraste, la observaron frustrada desde sus inicios por la estatización emprendida por el grupo encaramado al poder. La discusión no arribó a un consenso y los grupos se quedaron

30. "Poder y falsificación...”, El Libertario, n 65, febrero-marzo de 2012, p. 15.

31. "Balance de la Comisión...", 20 de julio de 1962, CDLJP/FLA. 
en sus respectivas trincheras. Con todo, los anarquistas bonaerenses resumieron:

Vale la pena destacar la importancia que tiene el hecho en sí de una discusión sobre un tema candente en el que, con toda libertad, los anarquistas han discrepado, y no han vacilado en aceptar, como cosa natural, el derecho de otros compañeros de sostener públicamente opiniones discrepantes. En esta época, en que se ha hecho un fetiche la disciplina partidaria, el monolitismo de partido y de la razón de la mayoría, hemos afirmado nuestro concepto de la libertad indeclinable de cada uno a sostener sus propios puntos de vista. ${ }^{32}$

Bajo esas premisas quizá ningún grupo ideológico ha sido tan tolerante y tan dado a debatir todas las cuestiones, aún las más nimias, que los anarquistas. Las disputas relativas a tácticas, principios y medios han sido parte inherente a su propio ser, a fin de ir cubriendo aquellas fallas o debilidades en su interpretación y acción sobre la realidad. Aún con "las mal-interpretaciones", como los anarco-bolcheviques o los plataformistas, nunca las discusiones redundaron en la "excomunión", la catalogación de "traidor", el aislamiento y menos en la persecución o purga de sus cuadros.

En consecuencia, e independientemente de haber sido minúsculo el contingente adherido a la Revolución cubana, se le abrieron los canales para que pudiera expresarse y debatírsele, nunca se les intentó silenciar. Tal fue el caso de algunas cartas publicadas en La Protesta, en las que se puso en tela de juicio la veracidad de las críticas y cuestionamientos a la Revolución. ${ }^{33}$ En México, el viejo magonista Mares Velasco publicó un breve texto en Tierra y Libertad en defensa de la Revolución; ${ }^{34}$ Víctor García dedicó varios escritos panegíricos a Fidel Castro, igual el editorialista Tariaco en Regeneración o el destacado militante Estaban Méndez quien escribió una carta a Rodolfo Aguirre, secretario de la FAM, donde expresó sus dudas sobre si los embates a la Revolución no estarian infundados. ${ }^{35}$ No obstante, las individualidades quedaron

32. "Debate sobre la cuestión cubana", CDLJP/FLA, 5 de septiembre de 1960.

33. "Por la Revolución cubana", La Protesta, no 8084, febrero de 1963, p. 2.

34. Mares Velasco, "Puntos...", Tierra y Libertad, no 221, septiembre de 1961, p. 4; Víctor García, "La Revolución cubana", Tierra y Libertad, n² 200-201, enero de 1960 pp. 16, 17 y19.

35. "Carta de Aguirre a Méndez", 12 de octubre de 1963, Archivo Esteban Méndez/ Instituto de Investigaciones Históricas de la Universidad Autónoma de Tamaulipas (AEM/IIH/UAT). 
eclipsadas, al final, por la intransigencia con que una facción de la $\mathrm{Fe}$ deración Anarquista Uruguaya defendió la Revolución.

Una explicación de la adhesión de la FAU a la Revolución cubana la proporcionó Luce Fabbri, quien declaró que a poco de quedar constituida, y gracias a su estrecho vínculo con el movimiento estudiantil, una pléyade de jóvenes se sumó a sus filas. Entre ellos un grupo marcado por el marxismo, quienes pronto se hicieron de gran influencia por su arrojo y tenacidad, adquiriendo en su seno un gran ascendiente, esto les permitió asaltar el consejo federal e iniciar una reestructuración orgánica, dando un vuelco hacia un comunismo más a tono con el leninismo. ${ }^{36}$

Entonces, el debate en torno a la Revolución cubana, se dio con mayor intensidad con la FAU. Agudizado al momento en que el movimiento específico latinoamericano impulsó una campaña por la libertad de los presos libertarios cubanos, formando, además, un bloque contra lo que empezaron a calificar como "castro-comunismo". En ese contexto la FAU emitió una declaración de respaldo a la Revolución, en la que puntualizó que ellos defenderian la Revolución en tanto beneficiara a los sectores

36. "Entrevista a Luce Fabbri realizada por Margaret Rago", Montevideo, enero de 1995 y 1996, Centro de Documentación e Investigación de la Cultura de Izquierdas (Cedinci). En sus memorias, Hugo Cores da argumentos símiles a los de Luce: "desde hacía ya un tiempo se estaba incorporando gente a la FAU que se definía como marxista. Nosotros mismos sosteníamos que "ni era federación ni era anarquista". Sobre Cuba rememoró: "en Uruguay se estaba bien informado acerca de lo que ocurría en Cuba. Desde los inicios del proceso revolucionario habian viajado personas de distintos partidos, sindicalistas, educadores, periodistas" (Cores, 2002). Sobre esto último valdría apuntar que Cores no mencionó, en sus memorias, dos cuestiones que a mi parecer son importantes. La primera, que los ácratas uruguayos recibieron información directa de los anarquistas cubanos desde el inicio del movimiento armado, es decir, estaban al tanto de los vaivenes de la Revolución y de su orientación; la segunda, la celebración, en abril de 1957, de la Conferencia Anarquista Americana (CAA), organizada por la Biblioteca Archivo Internacional Anarquista (BAIA) y la FAU. Por qué resulta importante lo anterior: primero, a la CAA asistieron dos anarquistas cubanos claves en el tema aquí tratado: Casto Moscú y Juan R. Álvarez (militantes de la ALC); segundo, a partir de este momento los movimientos uruguayo y cubano se mancomunaron; tercero, esto explicaria por qué a Alfredo Errandonea, Ricardo Vilaró y Washington Pérez, delegados de la FAU al Primer Congreso Latinoamericano de Juventudes (1960), los libertarios habaneros los recibieron con tanto beneplácito y se les tuvo la confianza suficiente para cederles toda clase de información sobre la realidad cubana, incluso documentación confidencial y orgánica de la ALC, con la intención de esclarecer el tema de la Revolución en el continente y así evitar los debates bizantinos, cosa que por supuesto no se logró porque los fauístas se quedaron con la documentación y no turnaron la información, como lo habian prometido a los cubanos. Véase "Las dictaduras...", La Protesta, n 8034, 2 da quincena de agosto de 1957, p. 3; "Conferencia Anarquista Americana", Solidaridad Obrera, n 647, 15 de agosto de 1957 , p. 3. 
populares, fortaleciera la independencia de las cooperativas y sindicatos, eludiera su burocratización y no cayera en "la aparente efectividad de la dictadura ni en el espejismo de los hombres fuertes, ni se enredara en los esquemas de la democracia representativa, del parlamento y de las elecciones políticas". Respaldándola mientras garantizara las libertades públicas, tendiera a la descentralización y a profundizar sus postulados sociales de humanismo y libertad. ${ }^{37}$

Esas declaraciones desconcertaron a los cubanos no sólo porque los uruguayos eran conocedores de lo realmente acontecido en Cuba, pues en sus manos estaban los informes salidos desde la isla, sino porque la Federación Uruguaya fue quien comisionó más militantes a Cuba en el marco de la celebración del Primer Congreso Latinoamericano de Juventudes. Tres fueron los delegados de la FAU que visitaron la Cuba revolucionaria y se reunieron con elementos de la CNT y la ALC, estos otorgaron a los fauístas toda "clase de informaciones y documentos, datos, paseos por el país", después de los cuales esos "militantes coincidieron, sobre el terreno, en calificar aquello de totalitario, dictatorial demagógico, corrupto y entregado a los designios del imperialismo soviético". Aún así, a su retorno a Montevideo, se negaron y prosiguieron su apoyo a la tesis de la revolución fidelista. ${ }^{38}$

Por eso el MLCE le recordó a la FAU que a sus delegados se les concedió todo tipo de informaciones, se les demostró la terrible y triste realidad de la Revolución, no se les regateó nada con la intención de fincar en ellos "un concepto claro y preciso sobre el sentido totalitario del régimen cubano mal llamado revolucionario". ${ }^{39}$ Para el MLCE nada justificaba la desorientación sobre la cuestión cubana, no valian las argucias de la distancia o la falta de información, pues el Movimiento reiteró a la FAU que, a sus tres comisionados, se le cargó de explicaciones y de todo tipo de información, donde se "ponían en claro la tremenda frustración que significaba el régimen fidelista para la Revolución cubana", los documentos le fueron entregados para que los turnaran al movimiento y este poseyera razones oportunas para enjuiciar la Revolución. ${ }^{40}$

Lo anterior condujo al secretario del MLCE, Abelardo Iglesias, a censurar a Alfredo Errandonea, uno de los delegados, sobre la manera equivoca de conducirse al quedarse "con todos los papeles para hacer uso personal de ellos", a su conveniencia. Cosa lamentable, acusó Iglesias, pues Errandonea expresó su simpatía y comprensión ante el peligro

37. "Manifiesto en defensa de la Revolución cubana", CDLJP/FLA, 27 de agosto de 1960.

38. "Carta del MLCE a la FAU", CDLJP/FLA, 24 de agosto de 1961.

39. Ibídem.

40. "Carta de Iglesias a Prince", CDLJP/FLA, 10 de agosto de 1961. 
cernido para el destino de Cuba por la intromisión de los comunistas en la vida pública, mas a su retorno a Uruguay respaldó al régimen encabezado por Fidel Castro. ${ }^{41}$

En respuesta al MLCE, los fauístas dejaron en claro que no modificarian su posición y seguirian apoyando a la Revolución contra todo y todos. Enunciaron no ser torpes para no percatarse de las inmensas fuerzas reaccionarias empecinadas en destruir la Revolución: los antiguos explotadores, el imperialismo norteamericano y los reaccionarios. Estos poderes, alegaron, sembraban el "terrorismo ideológico y psicológico a través del dominio y control de las agencias noticiosas, del cine, de la radio y la televisión", a ello se añadian las atentados, amenazas y ataques contra la población. ${ }^{42}$

A la Revolución no se le deseaba suprimir porque fuera una dictadura, apuntó la FAU, se le anhelaba finiquitar por ser el primer paso de la revolución latinoamericana, una alternativa, palpable, para enfrentar "una realidad social que requiere soluciones de fondo en sus tremendos problemas, que no entiende de la espera porque siente la urgencia de millones de seres que ya no pueden soportar más una vida inicua de explotación y de oprobio". Por esos motivos la defendería, eso no significaba, asentaron, ignorar que la Revolución no era portadora de un carácter socialista-anarquista, al contrario, revelaron conocer que la misma estaba enmarcada dentro de un espíritu nacionalista y sus estructuras respondian a un sistema de planificación dirigido por mecanismos centralizados y estatizantes. ${ }^{43}$

\section{Puntos finales}

La adhesión libertaria a la Revolución encontró su límite al momento en que desembarcaron en el continente las primeras denuncias cargadas desde Cuba, principalmente las relacionadas con los aparatos represivos, los cuales no fueron liquidados sino reactualizados y revestidos con un halo redentor, pero su esencia permanecía íntegra. Si en un principio los anarquistas justificaron el exterminio físico y simbólico de los antiguos tiranos y represores, ${ }^{44}$ su ética revolucionaria no podía permitir ni legitimar ni pasar por alto que excompañeros de armas fueran ajusticiados, encarcelados y perseguidos bajo la acusación de ser contrarrevolucionarios o mercenarios del imperialismo, por la llana

41. "Carta de Iglesias a Alfredo", CDLJP/FLA, agosto de 1961.

42. "Carta de la FAU al MLCE", CDLJP/FLA, 8 noviembre de 1961.

43. Ibídem.

44. "Los fusilamientos", La Protesta, no 8053, 2 da quincena de enero de 1959, p. 1; Tariaco, “Cosas que suceden", Regeneración, n 42, septiembre de 1959, p. 4. 
razón de oponerse a la centralización económica, a la edificación de un Estado todopoderoso, a la preeminencia de un reducido grupo por sobre los intereses mayúsculos del proletariado y, en última instancia, por su rechazo al viraje socialista de la revolución.

Esa situación denunciada por los ácratas cubanos, en un primer momento, mediante mensajes cifrados, fue captada de inmediato por quienes fueron víctima, en Rusia o en España, de los organismos represivos erigidos en nombre del comunismo. Como Fidel Miró, aprehendido y torturado por una cheká del Partido Socialista Unificado de Cataluña durante las jornadas de mayo de $1937 .{ }^{45}$ Miró, al conocer la pauta prohijada por la Revolución, no dudó en reconocer que la misma despertó un entusiasmo sin limites en las corrientes liberales e izquierdistas latinoamericanas, e hizo concebir la más cara ilusión de libertad y prosperidad para un futuro inmediato; mas, a dos años, la oportunidad se había malogrado y obligación era reconocerlo, aun cuando ciertos sectores del anarquismo (refiriéndose a la FAU) no admitieran la trágica realidad, pese a todo, consideró Miró, era imposible silenciar la traición por más tiempo. Traición, para ellos, por dar la espalda y desdeñar los principios humanistas, a la libertad y a la democracia y, en su lugar, implantar un régimen "dictatorial". Traición a su parecer, por someter a Cuba a un nuevo tipo de colonialismo. ${ }^{46}$

De ahí que, al clausurarse 1960, la casi totalidad de los libertarios asumieron una postura homogénea contra el castrismo y, con el amanecer de 1961, se abrió en el seno del acratismo otro tipo de meditaciones dirigidas contra la izquierda "embrujada" con el proceso cubano. ${ }^{47}$ Una de las reflexiones más lúcidas la expresó Lorenzo de Vedia desde La Protesta, quien puntualizó que todo revolucionario debía asumir ciertos principios básicos comunes a todos los seres humanos, siendo una obligación reconocerlos como portadores de una ética común a la totalidad de los pueblos. Es cierto, indudablemente, que las distintas realidades derivan en diferentes modos de acción, pero estos no pueden

45. "Ante los sucesos de Cataluña", La Obra, n 12, junio de 1937, p. 1.

46. Miró, "Contrarrevolución en Cuba", Reconstruir, n 12, mayo-junio de 1961, pp. 19-22.

47. Durante la década de 1960 fueron pocos los anarquistas que mantuvieron su apoyo, crítico o incondicional, a la Revolución, entre ellos un grupo de jóvenes franceses encabezados por Daniel Cohn-Bendit, quien tenía gran cobertura mediática por su destacada actuación durante el mayo francés. Razón por la que acaparó los reflectores durante la celebración del Congreso Anarquista Internacional celebrado en Carrara, Italia, en 1968, el cual brilló por el debate entablado sobre la Revolución cubana, entre "Dany el Rojo", como se lo llamaba, con Federica Montseny y Domingo Rojas, este en representación de mexicanos y cubanos. Ver Memoria... (2008), y "Ponencia de la FAM al Congreso...", 26 de julio de 1968, AEM/IIH/UAT. 
ni deben anular esa ética común ni esos principios indispensables a fin de garantizar una convivencia digna y decorosa. Ejemplo sería no realizar persecuciones por cuestiones ideológicas, principio que no puede ni debe cancelarse sea cual sea la realidad acontecida, menos en un régimen pretendido y presentado diferente y manumisor. ${ }^{48}$

\section{Bibliografía citada}

ASL (1960). Declaración de principios. Editorial Luz-Hilo.

Cores, H. (2002). Memorias de la resistencia. Ediciones de la Banda Oriental. Disponible en https://is.gd/aqpGKQ.

Domingo, J. (2009). El exilio republicano español en Cuba. Siglo XXI. Fernández, F. (2000). El anarquismo en Cuba. FAL.

Glondys. O. (2012). La Guerra Fría cultural y el exilio republicano español: Cuadernos del Congreso por la Libertad de la Cultura (1953-1965). CSIC. Iber, P. (2015). Neither peace nor freedom: the cultural Cold war in Latin America. Harvard University Press.

Iglesias, A. (1963). Revolución y dictadura en Cuba. Reconstruir.

Memoria del Congreso Internacional Anarquista de Carrara (2008). Biblioteca Antorcha. Disponible en http://goo.gl/hbqO4n.

Rama, C. y Cappelletti, Á. (comps.) (1990). El anarquismo en América Latina. Biblioteca Ayacucho.

Souchy, A. (1960). Testimonios sobre la Revolución cubana. Reconstruir.

48. Lorenzo, "En torno a la Revolución cubana", La Protesta, n 8082, septiembre de 1962, p. 2. 